\title{
Quality of care in the context of rights-based family planning
}

Anrudh K. Jain

Population Council

Follow this and additional works at: https://knowledgecommons.popcouncil.org/departments_sbsr-rh

Part of the Demography, Population, and Ecology Commons, Family, Life Course, and Society Commons, and the International Public Health Commons How does access to this work benefit you? Let us know!

\section{Recommended Citation}

Jain, Anrudh K. 2017. "Quality of care in the context of rights-based family planning," Policy brief. New York: Population Council. 


\section{Quality of Care in the Context of Rights-Based Family Planning}

The anticipated outcome of

improved service quality is

likely to be an improvement in the effectiveness and duration of contraceptive use and an improvement in women's and men's ability to achieve their own reproductive intentions.

\section{PROBLEM STATEMENT}

Every individual has the right to have children, if and when they want (UN, 1968; UNFPA, 1995). Many individuals, however, cannot implement this right in part because of community, familial, and religious impediments and in part because of obstacles they face in accessing and using family planning (FP) services. Rights-based approaches to health, sexual and reproductive health (SRH), and FP drew attention to many of these impediments including the AAAQ (Available, Accessible, Acceptable, and Quality) framework (UNCESCR 2000, 2016; Hardee et al. 2014; WHO, 2014; FP2020). Thus, rights-based FP includes quality but the reverse is not true because Bruce's (1990) quality of care framework (hereafter referred to as QoC framework) applied to the users of services and did not include the other AAA dimensions of services. Admittedly, services must be available before one can inquire about other dimensions of services, e.g., how acceptable, and of what quality.

The term quality has been used in many ways (see Box 1). The QoC framework largely focused on client-provider interactions. Since the General Comment 14 on right to health proposed good health as the main outcome, quality in this formulation largely focused on technical, clinical, or medical aspect of services. The VRBFP framework and FP2020 combines the two-a step in the right direction. However, subsequent articulation of quality in General Comment 22 on the right to SRH went back to a primary focus on the clinical aspect of services. The articulation of quality in these rightsbased approaches to some extent is circular as quality is defined in terms of services of 'good quality.' As there

\section{BOX 1: Approaches to Quality of Care}

Elements of Client-centered Quality of Care framework (Bruce 1990)

- Choice of contraceptive methods,

- Information given to clients,

- Technical competence,

- Interpersonal relations,

- Follow-up/continuity mechanisms, and

- Appropriate constellation

Quality in General Comment 14 on the right to health: "As well as being culturally acceptable, health facilities, goods and services must also be scientifically and medically appropriate and of good quality (UNCESCR 2000)."

Highest Quality in Voluntary, Human Rightsbased Family Planning (VRBFP) is articulated as "Scientifically and medically appropriate and of good quality-for example, full, free, and informed decisions; broad choice of methods continuously available; accurate, unbiased and comprehensive information; technical competence; high quality client-provider interactions; follow-up and continuity mechanisms; and appropriate constellation of services (Hardee et al. 2014)."

Quality defined by FP2020 as "Individuals have access to contraceptive services and information of good quality which are scientifically and medically appropriate. Quality of care is a multifaceted element that includes but is not limited to: a full choice of quality contraceptive methods; clear and medically accurate information, including the risks and benefits of a range of methods; presence of equipped and technically competent providers; and client-provider interactions that respect informed choice, privacy and confidentiality, and client preferences and needs (FP2020)."

Quality in General Comment 22 on right to SRH: "Facilities, goods, information, and services related to SRH must be of good quality, meaning that they are evidence-based and scientifically and medically appropriate and up-to-date (UNCESCR 2016)." 
is a conceptual overlap and some differences among these articulations of quality, there is a need to compare and, if possible, to reconcile the elements of quality to ensure that the conceptualization, measurement, and monitoring of quality are coherent and not encumbered by redundancy. Kumar (2015) concluded that "With some modification, the widely accepted Bruce quality framework, which has guided international FP for twenty-five years, could continue to serve us well going forward." This policy brief suggests five modifications to the QoC framework, which are based on the comparison of quality across frameworks, past experiences, and issues faced in measuring quality.

\section{SUGGESTED MODIFICATIONS TO THE QOC FRAMEWORK}

The following modifications to the framework are suggested based on this review:

1) The QoC framework did not explicitly include safety of contraceptive technologies as is done in the rights-based approaches. However, the element of technical competence in the QoC framework was defined as including "the competence of the clinical technics of providers, the observance of protocols, and meticulous asepsis required to provide clinical methods such as IUDs, implants, and sterilization." The safety of contraceptive technologies is assured by the regulatory agencies and thus, contraceptive methods included in FP programs are generally safe, if procured and managed appropriately. However, sometimes the lack of medical standards, counterfeit products or those from unqualified sources or expired drugs, and lack of infection prevention practices has led to unnecessary morbidity and mortality associated with contraceptive use. To ensure safety in contraceptive service delivery, the element of technical competence in the QoC framework can explicitly include attention to safety issues and can be restated as a

“competent provider to ensure safety and compliance with infection prevention practices in delivering services".

2) The element of information given to clients in the QoC framework referred to 'information imparted during service contact that enables clients to choose and employ contraception with satisfaction and technical competence,' which may be interpreted as one-way communication. The nature of a two-way communication between providers and clients was mentioned but not elaborated in the element of interpersonal relations of the QoC framework. This was modified in a parallel work on the assessment of quality in which Kumar et al. (1989) used the term 'information exchange' to denote two-way communication between providers and clients. In subsequent research related to quality, information exchange also included information solicited from clients about their reproductive intentions, prior use of contraception, and family circumstances. The information exchange process was useful in operationalizing the choice element at the client level by helping them to choose a method most appropriate to their needs and circumstances, and was also used in subsequent research on quality. It is suggested that the element of information given to clients be replaced by “information exchange and also explicitly include the component of solicitation of information and preferences from clients".

3) The QoC framework included the element of follow-up or continuity in care. However, this element can only be operationalized at the client-level through information given to clients about when to return for a follow-up visit, whether to give a written reminder for the date of follow-up, and by encouraging clients and providing them information to switch the method whenever the method they are starting does not remain suitable to their needs and circumstances. Subsequent research related to quality also focused on improving clientprovider interactions including providing guidance about switching (e.g. Costello et al 2001, Sathar et al. 2005). It is suggested that the element of information exchange be further expanded to include "information on followup requirements and guidance on the possibility of switching the method, provider, or service outlet".

4) The QoC framework emphasized quality in terms of the way clients are treated by the system providing services. The element of interpersonal relations implicitly included the treatment of clients with dignity and respect and maintaining their privacy and confidentiality. These items were included in the parallel work on the assessment of quality (Kumar et al. 1989). They were also included in subsequent research including data collected through the methodology of Situation Analysis. It is suggested that "dignity, respect, confidentiality and privacy be made explicit in the element of interpersonal relations, which will also make the QoC framework compatible with rights-based FP".

5) The six elements of quality may be divided among structure and process levels according to their appropriateness for improvement and measurement as well as the perspective of the respondent. The QoC framework distinguished three points from which to view quality: structure of the program, the service-giving process, and outcome of care (Bruce 1990). The distinction between structure and process is like the distinction usually made between quality of services and quality of care. Structure or quality of services refers to: (1) policy-level intention to provide an explicitly stated standard of care, and (2) the readiness of services to offer the intended standard of care. The service-giving process refers to the extent to which clients are offered and clients received the intended standard of care.

While all the six elements of quality are important at both structure and process levels, it has been difficult to operationalize and measure each of them at each level separately. Three elements seem to be particularly appropriate to ensure readiness of services: choice of methods, technical competence, and appropriate constellation of services. The service-giving process refers to the way clients are treated by the services and can incorporate the remaining three elements: information solicited from and given to clients, interpersonal relations, and follow-up/continuity mechanisms. However, the information exchange between providers and clients remains the main vehicle to operationalize and measure all elements at the point of care. 


\section{Box 2: Modified QoC Framework}

1. Structure (quality of services or readiness of services)

a. Choice (availability of the appropriate number and type of methods and required equipment

b. Availability of trained/competent provider in:

- Providing contraceptive methods safely

by ensuring compliance with infection

prevention practices

- Treating clients with dignity and respect

- Appropriate information exchange with clients

c. Availability of space to ensure audio and visual privacy

d. Availability of appropriate constellation of RH services

2. Service-giving process (quality of care)

a. Appropriate information exchange with clients to ensure:

- Selection of a method appropriate to client's needs and circumstances by soliciting information from them about their reproductive intentions, family circumstances, prior use of contraception, and preferred method; and by providing information on alternate methods appropriate to their needs

- Effective contraceptive use by informing clients about such items as how to use the method selected, potential side effects and how to manage them if they occur

- Continuity of care and contraceptive use by informing clients when to come back for resupply and possibility of switching the method, provider, or service outlet whenever the selected method/provider/outlet does not remain suitable

b. Interpersonal relations including:

- Treating clients with dignity and respect

- Ensuring audio and visual privacy and confidentiality

\section{MODIFIED QOC FRAMEWORK}

The modified QoC framework is shown in Box 2. No change is suggested in the element of choice, except that the availability of a method is reflected by the availability of commodities, equipment, and a provider competent in offering that method. No change is also suggested in the element of constellation of services. However, it has been difficult to measure this element because it cannot be ascertained whether a range of reproductive health $(\mathrm{RH})$ services at one place implies better quality of care for clients than FP services alone. Despite this difficulty and in view of the General Comment 22 on right to $\mathrm{SRH}$, this element is retained in the modified framework with the hope that it can better be operationalized and measured in the future. The element of technical competence is broadened to include competency in providing the method chosen, compliance with infection prevention practices, and information exchange with clients.

Thus, providers-the main contact between the system providing services and clients-assume considerable responsibility in their interactions with clients. The element of information given to clients is replaced by information exchange consisting of information solicited from clients to ensure the selection of a method appropriate to client's needs, preferences, and circumstances, information given to clients to ensure effective contraceptive use, and information given to clients to ensure continuity of care and contraceptive use. The element of interpersonal relations explicitly includes the treatment of clients with dignity and respect, and ensuring their privacy and confidentiality.

\section{ILLUSTRATIVE APPLICATION OF THE MODIFIED QOC FRAMEWORK}

Programmatic implications of the modified framework are mentioned in Box 3. Its application is illustrated below by considering the element of choice. Choice at the policy-level implies an explicitly stated policy about the number and type of contraceptive methods the program intends to offer to meet the different needs of clients. Five types of methods are usually recommended to meet five types of needs of clients and to ensure full choice (WHO, 2014). Readiness of services to offer a method can be ensured by having constant supply of information or counseling materials, commodities, equipment, and trained providers.

Choice at the point of care implies that providers offer various methods and help clients to select a method appropriate to their medical needs and circumstances. Moreover, choice

\section{Box 3: Programmatic Implications}

1. Policy level: Explicit policy about the standard of care the program intends to offer.

a. Number and type of methods

b. Guidelines for infection prevention

c. Guidelines for training of service providers

\section{Readiness of Services:}

a. Availability of counseling materials, infection prevention guidelines, equipment, supplies, and trained providers

b. Availability of commodities, equipment, and trained providers to ensure choice of methods

c. Availability of space for ensuring privacy

3. Client level: providers follow guidelines and protocols for infection prevention practices; solicit information from clients and offer method choice, provide information to ensure effective use of the method selected, follow-up visits, and possibility of switching; treat clients with dignity and respect and ensure their privacy and confidentiality. 
from the client's perspective implies that they receive the method appropriate to their needs and preferences. Similarly, operationalization of infection prevention practices at the policy level would imply a stated policy and related guidelines; at the service level, it would imply the availability of guidelines, equipment and material, and provider trained in implementing infection prevention practices, and at the client level, it would imply that these practices are used with all clients.

\section{CONCLUSIONS}

Over the past two decades, the QoC framework has become a cornerstone of FP programming. Many other dimensions of services are reported as a reason for nonuse of contraceptives. The FP programs have been concerned about improving access and reducing the cost to the client but at the same time making services sustainable and improving their effectiveness and efficiency. Nevertheless, access to FP services is not equitable: educated, wealthier, or urban women have better access to the available services from a range of sources than their more vulnerable counterparts, who are less educated, poor, or live in rural areas. Furthermore, adolescents and unmarried women may be discouraged to use these services because of perceived or actual discrimination by service providers. These dimensions of service delivery programs need to be analyzed to identify gaps within a country context and steps taken to remedy the obvious inequities in access to good quality services.

Similarly, the quality of services available at different types of service facilities and quality of care received by clients in a country need to be analyzed to identify gaps within a country context and steps taken to remedy the situation. For example, various types of contraceptive methods may not be available to meet the differing needs of women, and indeed men, depending on their life situations. Providers may not have appropriate training or necessary equipment to provide a method or it may not be available at the service facility. The highlighted recommended modifications to the QoC framework are likely to help identify these gaps, improve services, and develop standard metrics to measure various elements of quality at structure, process, and outcome levels. The anticipated outcome of these improved services is likely to be an improvement in the effectiveness and duration of contraceptive use and an improvement in women's and men's ability to achieve their own reproductive intentions in a healthful manner because of explicit inclusion of safety issues (compliance with infection control practices) and attention to two-way information exchange between service providers and clients. Furthermore, the modified framework will align it with the way the framework has been operationalized and used in practice and also with the rights-based approaches to health, $\mathrm{SRH}$, and FP.

\section{REFERENCES}

1. Bruce, J. 1990. "Fundamental Elements of the Quality of Care: A Simple Framework". Studies in Family Planning 21, 2: 61-91

2. Costello, M., M. Lacuesta, et al. 2001. "A Client-Centered Approach to Family Planning: The Davao Project." Studies in Family Planning, 32(4): 302-314.

3. Hardee, K., J. Kumar, K. Newman, L. Bakamjian, S. Harris, M. Rodriguez, and W. Brown. 2014. "Voluntary, Human Rights-based Family Planning: A Conceptual Framework.” Studies in Family Planning. 45(1): 1-18.

4. Kumar, Sushil, Anrudh Jain, and Judith Bruce. 1989. "Assessing the quality of family planning services in developing countries." Programs Division Working Papers No. 2:1-40. New York: The Population Council

5. Kumar, Jan. 2015. How Does Quality of Care Relate to a Rightsbased Approach to Family Planning Programs? Report prepared under a grant from the David \& Lucile Packard Foundation to the Population Council, May 15. New York: The Population Council

6. Sathar, Zeba, Anrudh Jain, Saumya Rama Rao, Minhaj Haque, and Jacqueline Kim. 2005. "Introducing Client-centered Reproductive Health Services in a Pakistani Setting." Studies in Family Planning 36, no. 3: 221-234.

7. United Nations (UN). 1968. "Final Act of the International Conference on Human Rights" (Proclamation of Teheran). 22 April-13 May. New York.

8. United Nations, Committee on Economic, Social and Cultural Rights (UNCESCR). 2000. General Comment No. 14, The right to the highest attainable standard of health (Article. 12 of the International Covenant on Economic, Social and Cultural Rights). Report on the Twenty-Second, Twenty-Third and Twenty-Fourth Sessions, Economic and Social Council Official Records, 2001, Supplement No. 2

9. United Nations, Committee on Economic, Social and Cultural Rights (UNCESCR). 2016. General Comment No. 22 on the right to sexual and reproductive health (article. 12 of the International Covenant on Economic, Social and Cultural Rights). United Nations: Economic and Social Council E/c.12GC/22 (2 May).

10. United Nations Population Fund (UNFPA). 1995. "Report of the International Conference on Population and Development." New York: UNFPA.

11. World Health Organization (WHO). 2014. “Ensuring human rights in the provision of contraceptive information and services: Guidance and recommendations." Geneva: WHO.

\section{ACKNOWLEDGMENTS}

This brief has been prepared by Anrudh K. Jain for the Measuring and Monitoring Quality of Services and Quality of Care project funded by a grant from the David and Lucile Packard Foundation to the Population Council. We gratefully acknowledge the support and encouragement of the Foundation to continue research on the current state of quality of care. Comments can be sent to the author at ajain@popcouncil.org.

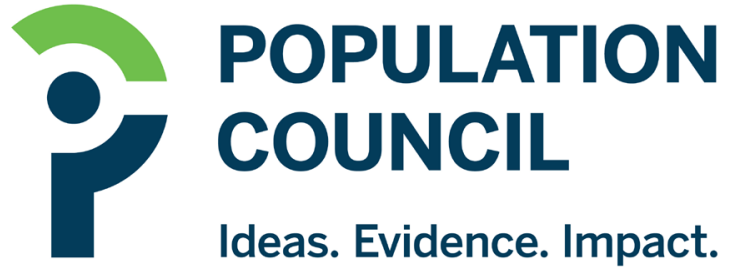

